\title{
RAILROAD PLOTS
}

\section{Kotelnikov Vladimir Alekseevich ${ }^{1}$}

Professor, Institute of Russian Literature

(Pushkinskij Dom) of the Russian Academy of Sciences,

Saint-Petersburg, Russia.

(date of receiving: December, 2020; date of acceptance: January, 2021)

\begin{abstract}
The article, among other meaning-forming factors of the narrative text, highlights the specific locus of the railway, which plays a significant role in Russian literature of the 19th and then 20th centuries. It is shown that in the space of the railway car the worldview and behavior of people change. This is due to the nature of the microsociium that develops in such a space. It can occur a variety of, unpredictable meetings, there is an attraction or repulsion of the met, communication can expose the most intimate depths of personality or mask them. All this is done in conditions of heightened mental tension, under the influence of such factors, which rarely occur in systemic communicative acts. Such phenomena is demonstrated by the examples of Leo Tolstoy's novel "Kreutzer Sonata", his novel "Resurrection", Dostoevsky's travel notes and his novel "The Idiot", works by Ivan Bunin ("The Life of Arseniev", "Penguins" etc.), Vladimir Nabokov ("Other Shores", "Glory" and etc.)
\end{abstract}

Keywords: Russian Literature, Railway, Locus of Train, Leo Tolstoy, Dostoevsky, Bunin, Nabokov.

1. E-mail: vladiko@VK9485.spb.edu 


\title{
ЖЕЛЕЗНОДОРОЖНЫЕ СЮЖЕТЫ
}

\section{Котельников Владимир Алексеевич ${ }^{1}$}

Профессор, Институт русской литературы

(Пушкинского Дома) Российской Академии наук, Санкт-Петербург, Россия.

(дата получения: декабрь 2020 г.; дата принятия: январь 2021 г.)

\begin{abstract}
Аннотация
В статье среди прочих смыслообразующих факторов повествовательного текста выделяется специфический локус железной дороги, который в русской литературе XIX, а затем и XX вв. играет существенную роль. Показано, что в пространстве железнодорожного вагона меняются мировосприятие и поведение людей. Это связано с характером микросоциума, который складывается в таком пространстве. В нем могут происходить самые разнообразные, непредсказуемые встречи, возникать притяжение или отталкивание встретившихся, общение может обнажать самые интимные глубины личности или маскировать их. Все это совершается в условиях повышенной психической напряженности, под влиянием таких факторов, которые редко возникают в системных коммуникативных актах.

Такие явления демонстрируются на примерах повести Льва Толстого «Крейцерова соната», его романа «Воскресение», путевых заметок Достоевского и его романа «Идиот», произведений И. Бунина («Жизнь Арсеньева», «Пингвины» и др.), В. Набокова («Другие берега», «Подвиг» и др.).
\end{abstract}

Ключевые слова: Русская Литература, Железная Дорога, Локус Поезда, Лев Толстой, Достоевский, Бунин, Набоков.

1. E-mail: vladiko@VK9485.spb.edu 


\begin{abstract}
Введение
В ряду смыслообразующих факторов повествовательного текста существенную роль играет то, что называется «место действия». Хотя оно может иметь нейтральное значение в отношении события или персонажа, но в большинстве случаев оказывается весьма важно, в каком именно пространстве, в какой обстановке происходит событие и действует герой. В литературе девятнадцатого века, при всем огромном разнообразии вещественного наполнения и колорита, «места действия» сводились к нескольким типам локусов: дома, города, природы, с фрагментированием пространства и дифференциацией по тем или иным признакам.

Однако в том же столетии появился новый специфический в своем подвижном содержании локус - железная дорога, связующая урбанистические локусы и покрывающая разрастающейся сетью осваиваемое цивилизацией пространство. Железная дорога интенсивно социализирует это пространство, являясь массовым общественным транспортом, связывает и перемещает людей, определяет их состояния и поведение, когда они оказываются в пространстве поезда и на прилегающей к нему территории.
\end{abstract}

Собственно, общественный транспорт был и до распространения железнодорожного сообщения, таков, в частности, дилижанс. Но при поездке в нем, при его малой скорости, картина окружающей среды для путешественников менялась слишком медленно, изменения ее в таком темпе не имели существенного значения для происходящего. А главное неупорядоченность и стесненность внутреннего пространства дилижанса нарушала границы индивидуально-личной сферы пассажиров, зачастую создавала неблагоприятную психологическую атмосферу и скорее препятствовала, чем способствовала общению попутчиков. На морском судне до девятнадцатого века долгое путешествие выводило людей из порядка 
обыденной жизни, в нем был, с одной стороны, момент экстремальности, а с другой - момент монотонности: в течение многих дней, подчас и недель, вокруг простиралось однообразное, даже при случавшихся штормах, пространство, притупляющее впечатления, не влияющее на мысль и чувства, кроме того, круг попутчиков вынужденно оставался одним и тем же, как правило, с не меняющимися отношениями между людьми.

\section{Основная часть}

Железная дорога стала особым феноменом. С ней в русской литературе связано немало сюжетов. Мы не будем касаться трагических финалов, которыми автор завершал сюжетные линии героев в соответствии со свой художественной и этической задачей. Здесь место действия находилось вне поезда, но было обусловлено его движением, как то произошло с Анной Карениной (Толстой 1982. 363-364), с героиней А. А. Блока (Блок 1960. 260261), с героем В. М. Гаршина (Гаршин 1955. 307).

Человек, едущий в поезде, находился в двойственных отношениях к окружающей среде с ее природным, социальным и культурным содержанием: он и убегал от нее, отчуждался от нее в обособленном движущемся пространстве вагона, и был связан с ней впечатлениями, ожиданиями и поступками. Быстро сменяющиеся по ходу движения фрагменты среды создавали сильный и зачастую непредсказуемый ряд образов, возможных событий и встреч. Двойственно и внутреннее пространство вагона: оно замкнуто в себе, автономно, оказывается жилищем для занявших его пассажиров, но оно временно и проницаемо для воздействий изменчивой окружающей среды, каждый обитатель вагона может внезапно его покинуть, и так же внезапно может войти в него другой, что вносит момент изменчивости и случайности в этот микросоциум. В нем могут происходить самые разнообразные, непредсказуемые встречи, возникать притяжение или 
отталкивание встретившихся, общение может обнажать самые интимные глубины личности или маскировать ее - и все это совершается в условиях повышенной психической напряженности, под влиянием таких факторов, которые редко возникают в системных коммуникативных актах.

В повести Льва Толстого «Крейцерова соната» (1890) герой рассказывает о совершенном им убийстве жены. Чтобы решиться на этот рассказ, Позднышеву нужна была особая ситуация общения, и писатель создает ее в поезде, где случайно встречаются люди разных социальных положений и разного психического склада. Предшествовавший разговор попутчиков об отношениях между мужчиной и женщиной дал тематическое основание для ситуации. Позднышев до поры молчал и избегал общения, когда же вступил в разговор, то внес в него резкий диссонанс своей необъяснимой для всех возбужденностью и потом шокировал собеседников признанием, что он тот самый человек, чье нашумевшее преступление, видимо, известно его попутчикам. Так завершается первая вагонная встреча персонажа, где он выступает в роли enfant terrible в обычной дорожной беседе на злободневную тему. Вторая встреча - сближение с едущим здесь же повествователем, с которым у Позднышева вдруг возникают доверительные и сочувственные отношения. Когда они остаются наедине, герой, которому «тяжело молчать», рассказывает свою историю во всех ее событийных и психологических подробностях. Разумеется, случайная встреча в поезде есть литературный прием, необходимый писателю для обнажения чувств и мыслей персонажа, но столь сильный порыв откровенности последнего мотивируется еще и особым психическим состоянием его. По ассоциации с давним эпизодом в поезде же, когда Позднышева охватил приступ ревности, он сейчас признается: «Боюсь я вагонов железной дороги, ужас находит на меня» и предполагает, что вообще «железная дорога возбуждающе действует на людей» (Толстой 1982-а. 184185). Именно в состоянии такого болезненного возбуждения, страха перед 
современным обществом (как позже будет бояться его Нехлюдов в романе «Воскресение», 1899) и вместе с тем в силу неудержимого влечения к людям Позднышев решается рассказать всё.

Помещая Нехлюдова в вагон третьего класса, Толстой преследует прежде всего свои моральные цели: здесь герой встречается с народом и непосредственно видит ту «правду», по законам которой народ живет. Нехлюдов, по замыслу Толстого, должен здесь непреложно убедиться, что страсть, ненависть, преступление, всякое зло «покрывается любовью» в человеческих отношениях Попутчиком героя оказывается Тарас, рассказывающий о своей жене, пытавшейся отравить его и свекра со свекровью. В отличие от разрешения семейной коллизии в «Крейцеровой сонате» в семье Тараса все прощают преступницу, и это вызывает в рассказчике и слушателях чувство умиленного удовлетворения. Безусловность народной «правды» поддерживается у Толстого всей природной средой, сопутствующей поезду, несущей в себе естественное добро и вторгающейся в вагон солнечным светом, красками растений, свежестью дождя. Встреча в поезде играет решающую роль в радикальном изменении нравственных и социальных приоритетов и поведения героя: «Да, совсем новый, другой, новый мир, - думал Нехлюдов, глядя на эти сухие, мускулистые члены, грубые домодельные одежды и загорелые, ласковые и измученные лица и чувствуя себя со всех сторон окруженным совсем новыми людьми с их серьезными интересами, радостями и страданиями настоящей трудовой и человеческой жизни» (Толстой 1983. 372).

Достоевский полагал, что пассажиры поезда дают очень богатый материал для характеристики самосознания русского человека и его социального поведения; он продемонстрировал это в заметках «Маленькие картинки (в дороге)» (1874). «Ну, вот мы входим в вагон. Русские люди классов интеллигентных, являясь в публику и сбиваясь в массу, всегда становятся 
любопытны для поучающегося наблюдателя; но в дороге особенно. У нас в вагонах заговаривают друг с другом туго; особенно характерны в этом отношении самые первые мгновения пути. Все как бы настроены друг против друга, всем как-то не по себе; оглядываются с самым недоверчивым любопытством, смешанным непременно с враждебностью, стараясь в то же время сделать вид, что не только не замечают один другого, но и не хотят замечать» (Достоевский 1980. 159). Это происходит оттого, что средний русский человек не может сразу определить свое место и социальное амплуа в кругу встретившихся в вагоне пассажиров и не имеет готовых форм общения с незнакомым человеком. Оттого общение вначале затруднено, зато «потом расходятся так, что иной раз и не удержишь» (Достоевский 1980. 160). Свойственные русским жажда общения и боязнь начать первым создают мучительную напряженность в замкнутом вагонном пространстве, пока «ктонибудь первый решится разбить стекло и завязать хоть что-нибудь вроде общего разговора. На железных дорогах это разбитие стекла происходит иногда довольно забавным образом, но всегда почти несколько иначе, чем на пароходах» (Достоевский 1980. 162) - там «пространство и время изменяют условия радикально» (Достоевский 1980. 167), замечает Достоевский: в отличие от вагона пассажиры на пароходе «не так сбиты вместе, публика не рискует образовать из себя кучу, не так быстро летят, не так подчинены необходимости, закону, минуте» (Достоевский 1980. 166).

В вагоне сгущенность человеческой массы, подвижные комбинации социальных типов, скорость перемещения создают возможность «пренеожиданных встреч» (Достоевский 1980. 166) и вторжения в общение «фантастического элемента», по выражению Достоевского, - вроде того господина, который без всякого повода начинает во всеуслышание рассказывать «свою собственную автобиографию», причем подчас «с самыми интимными, а иногда даже и чудесными, подробностями» (Достоевский 1980. 162). 
Все эти «картинки» были хорошо известны много ездившему в поезде Достоевскому задолго до написания цитированных выше заметок, и «ситуацию поезда» он не раз использовал в художественных и очерковых текстах. Встреча в вагоне дает начало главным персонологическим и сюжетным линиям романа «Идиот» (1868). Однако возможность свести различные человеческие типы в их тесном взаимодействии нужна здесь писателю уже не для общей «картинки», а для того, чтобы возможный только на железной дороге «случай так странно посадил их друг против друга в третьеклассном вагоне петербургско-варшавского поезда» (Достоевский 1973. 5 ) - для создания своего рода «антропологического ансамбля», который будет разыгрывать психологические и идейные драмы романа.

В доэмигрантском творчестве И. А. Бунина локус поезда редок, беден содержательно и функционально, хотя Бунин тогда едва ли не больше, чем другие писатели, ездил по железной дороге. В рассказе «Отто Штейн» (1916) «великолепный» поезд нужен лишь для перемещения героя из Берлина в Геную; мелькающие за вагонным окном поля, перелески, города свидетельствуют только о местности и скорости движения и вполне чужды «самоуверенному и гордому» Отто, который везде чувствует себя «человеком высшей расы» (Бунин 1966. 406-410); чужд ему и сам поезд, средство осуществления его честолюбивых целей. Для Казимира Станиславовича (в одноименном рассказе 1916 года), едущего из Киева в Москву по какому-то таинственному вызову, «купе второго класса, серое, тусклое» уже получает некоторое собственное значение: в несчастное, убогое существование героя оно вносит «ощущение роскоши, комфорта», «вагонное тепло, запах калорифера и тугое постукивание молоточков в нем» напоминают ему о неких «других временах» (Бунин 1966. 341). Но тема его прошлой жизни не получает развития, и «вагонный» эпизод быстро исчерпывается без всяких последствий в повествовании. 
Зато позже, уже в эмиграции, те же самые подробности обстановки в вагоне, но ярче окрашенные и дополненные множеством других, не появлявшихся у Бунина прежде, восстанавливаются писателем в автобиографической ретроспективе и входят в «Жизни Арсеньева» (1928) в лирический пассаж о «других временах» собственно бунинской жизни: «Ах, эти заносы, Россия, ночь, метель и железная дорога! Какое это счастье - этот весь убеленный снежной пылью поезд, это жаркое вагонное тепло, уют, постукивание каких-то молоточков в раскаленной топке <..>, полусвет фонаря за синей занавеской, и все растущий, качающий, убаюкивающий на бархатном пружинном диване бег <...> (Бунин 1966-б. 98-99).

С 1920-х годов локус поезда играет в прозе Бунина более существенную роль. В нем происходит реальное соединение с возлюбленной и бегство в рай дикой природы («Кавказ», 1937), встреча с возлюбленной в воспоминаниях, когда поезд проходит мимо мест былых событий («Руся», 1940). Несколько миниатюр 1930 года («Первый класс», «Канун») - натурные зарисовки вагонных сценок с намеченными в них социальными коллизиями предреволюционной эпохи.

Но наполнение пространства вагона низовой человеческой массой вызывает у Бунина реакцию отталкивания, это всегда отрицательная встреча (если не считать этнографического интереса автора к экзотике местного населения в рассказе «Третий класс», 1921). Преобладающими в этом случае мотивами были мотивы чувственные и эстетические. Стремящийся добраться до Крыма, до мест отцовской молодости автобиографический герой «Жизни Арсеньева» вынужден ехать по чужому билету в почтовом поезде, где он оказывается в «тесноте и мерзости», каких никогда не испытывал. Тогда он еще мог отвернуться от «тяжко-безобразной картины» спящих вповалку людей и отдаться созерцанию южной природы, которая по ходу поезда становилась все прекрасней, и в Севастополе он с тем большим наслаждением упивается 
роскошью юга, что остается наконец один и «все то огромное, мужицкое, что везли мы с собой, по дороге растаяло» (Бунин 1966-б. 174-176). После крушения всей прежней жизни в России столкновение рассказчика в вагоне с низовой массой («Несрочная весна», 1923) уже не может разрешиться уходом во внешний мир, который стал «вовеки непоправимой мерзостью» (Бунин 1966-а. 127), и это из него явился сидевший напротив рассказчика «русый мужик, большой, самоуверенный», куривший, плевавший на пол, храпевший и испускавший зловоние (Бунин 1966-а. 119). Вторая встреча произошла в тамбуре того же вагона - с знакомым рассказчика, бывшим профессором, который оказывается не только жертвой внешнего мира, но теперь и частью его, найдя свое место на жалком наделе возле своего бывшего имения. Обе встречи в поезде утверждают рассказчика в чувстве окончательной «отчужденности от этого “советского” вагона» (Бунин 1966-а. 128) и в решимости уйти в «”Элизей минувшего”, как бы в некий сон, блистающий подобием той яркой и разительно живой жизни, в которой застыли мертвецы с лазурными глазами в пустом дворце в подмосковных лесах» (Бунин 1966-а. 126).

Мотивы реальных событий и встреч прежней жизни, мотивы ухода в сны былого, преображаясь, возникают вновь и в рассказе «Пингвины» (1929) соединяются в локусе поезда, образуя почти эсхатологическую картину последнего земного путешествия. Рассказчик видит себя во сне в счастливую свою пору едущим в поезде на юг по «России того времени». «Поезд идет быстро и полон, но полон как будто неживыми. И в тех необыкновенно ровных степях, где идет он, тоже так безжизненно, скучно, словно не осталось ни малейшего смысла их существования» (Бунин 1966-а. 391). Таково завершение бунинских «отрицательных встреч» в поезде.

Железнодорожный вагон, именно международный вагон Норд-Экспресса, был предметом детских вожделений - в виде модели в окне агентства на 
Невском - и поэтизируемых позднее воспоминаний о семейных поездках из Петербурга в Париж В. Набокова. В «Других берегах» (1954) быстрое движение вагона через многообразие европейских ландшафтов в соотношении с маленьким мирком внутри вагона дает писателю неисчерпаемый материал для игры впечатлений и воображения. Здесь нет и не может быть чужих (случайный попутчик в четвертом купе однажды упомянут и более не появляется): вагон - дом повествователя, населенный семьей и слугами, внешний мир - объект наблюдений и манипуляций. Возможно «соприкосновение между экспрессом и городом», через который проходит поезд, но оно для повествователя - только «повод вообразить себя вон тем пешеходом и за него пьянеть от вида длинных карих романтических вагонов, с черными промежуточными гармониками и огненными на низком солнце металлическими буквами <..>» (Набоков 2003. 236). Все вещи и события внутри и вне вагона заключены в эгосферу повествователя и не отмечены проблемностью реального мира; прихотливое психологическое и литературное оформление их придает эгосфере Набокова почти герметический характер.

Повторяемость локуса поезда и связанных с ним мотивов (из чисто автобиографических текстов они переходят в художественные и обратно) подчас ведет у Набокова к прямой метафоризации: поезд - жизнь героя. В поезде герой встречается с самим собой в разных возрастах, с близкими и друзьями разных эпох жизни. Мартыну в его нескончаемых скитаниях («Подвиг», 1930) кажется, «что он никогда не выходил из экспресса, а просто слонялся из одного вагона в другой, и в одном были молодые англичане, Дарвин, торжественно берущийся за рукоять тормоза, в другом - Алла с мужем, а не то - крымские друзья, или храпящий дядя Генрих <...>. А тут, в этом спальном вагоне, тут ехало, должно быть, детство его; дрожа, освобождало кожаную сторку, а если пройти дальше, там - вагон-ресторан, и отец с матерью обедают < .. >» (Набоков 2001. 212-213). 
Встречаемые в поезде люди в разной степени отчетливо и содержательно видны сквозь слои эгосферы героя (повествователя, автора). Устремленный к своей цели и в само́м дорожном волнении усматривающий «необходимую тренировку», Мартын цепко и четко схватывает по пути те вещи и лица, на которых может испытать свою способность осуществить задуманное. И сосед по отделению вагона, пожилой француз, вырисовывается так четко и подробно потому, что его поведение убеждает Мартына, что его камуфляж безупречен. Все же остальные пассажиры сливаются для героя в «сонную мешанину беспомощных, полураздетых тел» (Набоков 2001. 209-212). А герой «Волшебника» (1939) почти не различает сквозь свою эгосферу, густо испещренную знаками и образами его эротических вожделений, сидевшую напротив него в вагоне попутчицу и не осознает, почему она вдруг перешла в другое отделение (Набоков 2003. 68-70).

Набоков не пренебрегает использовать вагон как место банального знакомства героя с женщиной. В жизни Хью Персона («Transparent things», 1972) встреча с Армандой была значительным событием и окрашена она в поэтичные тона мировосприятия этого персонажа. Встреча Кости с госпожой Бергман («Хват», 1932) дает толчок пошлым мыслям и подлому поведению самодовольного персонажа, что излагается автором в тоне презрительной иронии.

В сюжете реконструкции жизни умершего персонажа («The real life of Sebastian Knight», 1941) важную роль сыграла случайная встреча в вагоне с сыщиком Зильберманном. И символическое значение получает «невстреча», на которую обречен профессор Пнин («Pnin», 1957), едущий в почти пустом вагоне ошибочно выбранного им поезда.

Несколько необычное для Набокова развитие темы дано в рассказе «Облако, озеро, башня» (1937). Скромный и кроткий Василий Иванович выигрывает билет на увеселительную поездку и оказывается в «вагончике 
сугубо третьего класса» в компании немцев идиотического склада с садистическими наклонностями. И если движение поезда поначалу дает ему «наслаждаться мимолетными дарами дороги», то тем более чудовищен контраст между прелестным пейзажем за окном и монструозными спутниками героя: «все они сливались постепенно, срастаясь, образуя одно сборное, мягкое, многорукое существо, от которого некуда было деваться. Оно налезало на него со всех сторон». Они ежеминутно насилуют его, не позволяя уклониться от «прогулки», которая превращается в «какое-то приглашение на казнь» (Набоков 2004. 589) и приобретает черты кафкианской фантасмагории.

\section{Заключение}

Во второй половине девятнадцатого века, а затем и в последующую эпоху некоторые русские писатели проницательно заметили и с немалым литературным эффектом использовали в сюжетном и персонологическом планах новое «место действия», возникшее в современной цивилизации, пространство в движущемся поезде. Оно оказывалось в особых отношениях с меняющейся по ходу движения окружающей средой, главное же - в железнодорожном локусе складывались такая специфическая обстановка и такой микросоциум, в которых резче выявлялись черты персонажей, в этом локусе находящихся.

\section{Литература}

1- Блок А. А. (1960). Блок А. А. На железной дороге // Блок А. А. Собрание сочинений. В 8 т., Т. 3. - М., - Л.: Государственное издательство художественной литературы.

2- Бунин И. А. (1966). Бунин И. А. Собрание сочинений. В 9 т., Т. 4. - М.: Изд-во «Художественная литература».

3- Бунин И. А. (1966-а). Бунин И. А. Собрание сочинений. В 9 m., Т. 5. - М.: Издво «Художественная литература». 
4- Бунин И. А. (1966-б). Бунин И. А. Собрание сочинений. В 9 m., Т. 6. - М.: Издво «Художественная литература».

5- Гаршин В. М. (1955). Гаршин В. М. Сигнал // Гаршин В. М. Сочинения. М.: Государственное издательство художественной литературы.

6- Достоевский Ф. М. (1980). Достоевский Ф. М. Маленькие картинки (в дороге) // Достоевский Ф. М. Полное собрание сочинений. В 30 т., Т. 21. - Л.: Изд-во «Наука».

7- Достоевский Ф. М. (1973). Достоевский Ф. М. Идиот // Достоевский Ф. М. Полное собрание сочинений. В 30 т., Т. 8. - Л.: Изд-во «Наука».

8- Набоков В. В. (2001). Набоков В. В. Подвиг // Набоков В. В. Собрание сочинений русского периода. В 5 т., Т. 3. - СПб.: Изд-во «Симпозиум».

9- Набоков В. В. (2003). Набоков В. В. Другие берега // Набоков В. В. Собрание сочинений русского периода. В 5 т., Т. 5. - СПб.: Изд-во «Симпозиум».

10- Набоков В. В. (2004). Набоков В. В. Облако, озеро, башня // Набоков В. В. Собрание сочинений русского периода. В 5 т., Т. 4. - СПб. Изд-во «Симпозиум».

11- Толстой Л. Н. (1982). Толстой Л. Н. Анна Каренина // Толстой Л. Н. Собрание сочинений. В 22 т., Т. 9. - М. Изд-во «Художественная литература».

12- Толстой Л. Н. (1982-а). Толстой Л. Н. Крейщерова соната // Толстой Л. Н. Собрание сочинений. В 22 т., Т. 12. - М. Изд-во «Художественная литература».

13- Толстой Л. Н. (1983). Толстой Л. Н. Воскресение // Толстой Л. Н. Собрание сочинений. В 22 т., Т. 13. - М. Изд-во «Художественная литература».

\section{Bibliography}

1- Blok A. A.(1960). Blok A. A. Na zheleznoj doroge // Blok A. A. Sobranie sochinenij. V 8 t., T. 3. - M., - L.: Gosudarstvennoe izdatel'stvo hudozhestvennoj literatury.

2- Bunin I. A. (1966). Bunin I. A. Sobranie sochinenij. V 9 t., T. 4. - M.: Izd-vo «Hudozhestvennaja literatura».

3- Bunin I. A. (1966-a). Bunin I. A. Sobranie sochinenij. V 9 t., T. 5. - M.: Izd-vo «Hudozhestvennaja literatura».

4- Bunin I. A. (1966-b). Bunin I. A. Sobranie sochinenij. V 9 t., T. 6. - M.: Izd-vo «Hudozhestvennaja literatura».

5- Garshin V. M. (1955). Garshin V. M. Signal // Garshin V. M. Sochinenija. - M.: Gosudarstvennoe izdatel'stvo hudozhestvennoj literatury. 
6- Dostoevskij F. M. (1980). Dostoevskij F. M. Malen'kie kartinki (v doroge) // Dostoevskij F. M. Polnoe sobranie sochinenij. V 30 t., T. 21. - L.: Izd-vo «Nauka».

7- Dostoevskij F. M. (1973). Dostoevskij F. M. Idiot // Dostoevskij F. M. Polnoe sobranie sochinenij. V 30 t., T. 8. - L.: Izd-vo «Nauka».

8- Nabokov V. V. (2001). Nabokov V. V. Podvig// Nabokov V. V. Sobranie sochinenij russkogo perioda. V 5 t., T. 3. - SPb.: Izd-vo «Simpozium».

9- Nabokov V. V. (2003). Nabokov V. V. Drugie berega // Nabokov V. V. Sobranie sochinenij russkogo perioda. V 5 t., T. 5. - SPb.: Izd-vo «Simpozium».

10- Nabokov V. V. (2004). Nabokov V. V. Oblako, ozero, bashnja // Nabokov V. V. Sobranie sochinenij russkogo perioda. V 5 t., T. 4. - SPb. Izd-vo «Simpozium».

11- Tolstoj L. N. (1982). Tolstoj L. N. Anna Karenina // Tolstoj L. N. Sobranie sochinenij. V 22 t., T. 9. - M. Izd-vo «Hudozhestvennaja literatura».

12- Tolstoj L. N. (1982-a). Tolstoj L. N. Krejcerova sonata // Tolstoj L. N. Sobranie sochinenij. V 22 t., T. 12. - M. Izd-vo «Hudozhestvennaja literatura».

13- Tolstoj L. N. (1983). Tolstoj L. N. Voskresenie // Tolstoj L. N. Sobranie sochinenij. V 22 t., T. 13. - M. Izd-vo «Hudozhestvennaja literatura».

HOW TO CITE THIS ARTICLE

Котельников, В. (2021). RAILROAD PLOTS. Issledovatel'skiy

Zhurnal Russkogo Yazyka I Literatury, 9(1). 27-42.

DOI: $10.52547 /$ iarll.17.27

URL: https://www.journaliarll.ir/index.php/iarll/article/view/151 


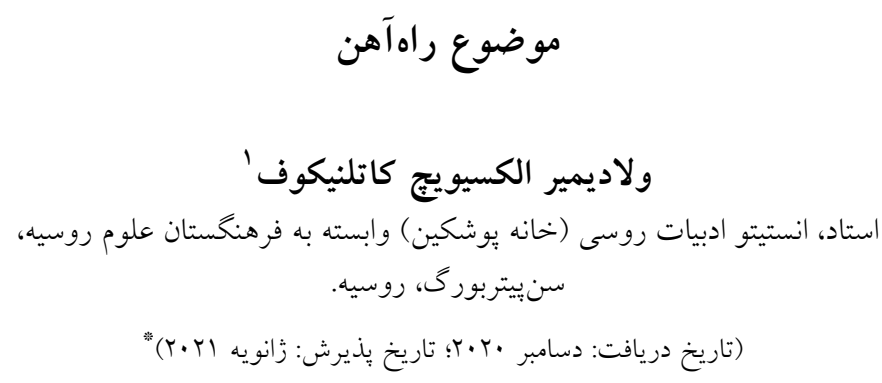

جكيده

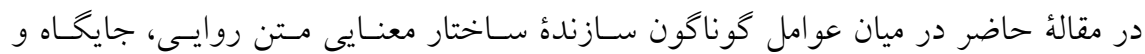

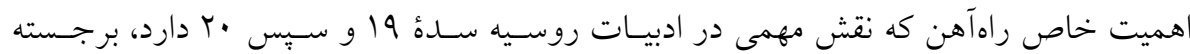

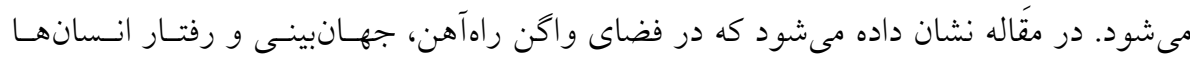

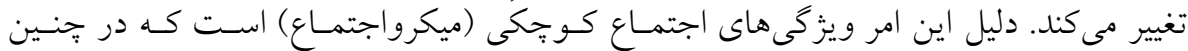

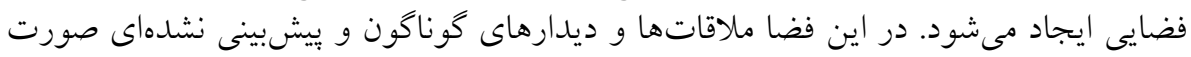

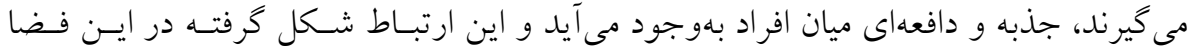

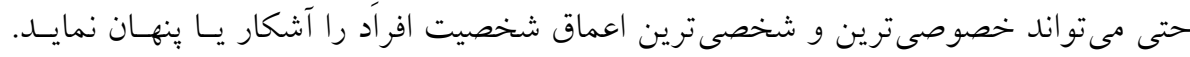

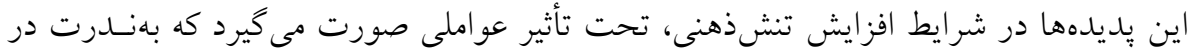

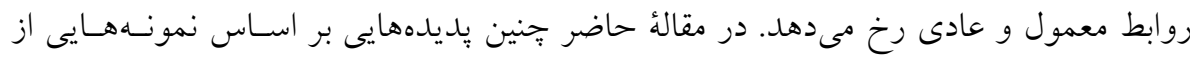

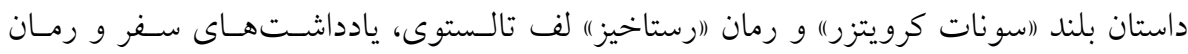

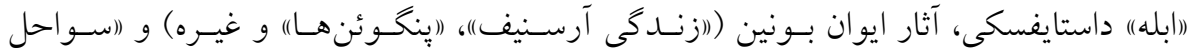

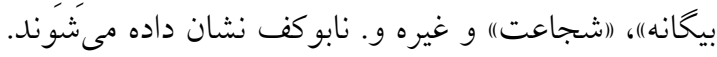

وازخان كليدى: ادبيات روسى، راهآهـن، فـضاى قطـار، لـف تالـستوى، داستايفسكى، بــونين، نابو كف.

1. E-mail: vladiko@VK9485.spb.edu

$$
\text { * نوع مقاله: علمى - يزوهشى }
$$

